\title{
Interactive comment on "Brief Communication: New evidence further constraining Tibetan ice core chronologies to the Holocene" by Shugui Hou et al.
}

\section{Anonymous Referee \#2}

Received and published: 28 December 2020

Hou et al. present the $14 \mathrm{C}$ dating results of water-insoluble organic carbon (WIOC) fraction of carbonaceous aerosols from two new ice cores reaching bedrock (i.e., the Zangser Kangri (ZK) glacier and the Shulenanshan (SLNS) glacier) in northern Tibetan Plateau. These $14 \mathrm{C}$ dates suggest that the bottom ages of these two ice cores are $\sim 8.90 \pm 0.57$ and $\sim 7.46 \pm 1.79 \mathrm{ka}$, respectively. Considering the newly obtained bottom ages of these two ice cores and other bottom ages determined absolutely for other ice cores on the Tibetan Plateau, the authors therefore argue for the Holocene origin of Tibetan ice cores and challenge the reliability of chronologies of the Guliya and Dunde ice cores. 
The dates from these two new ice cores are no doubt essential for establishing their own absolute chronologies. Based on the bottom ages of these two ice cores along with other ice cores' bottom ages to argue the Holocene origin of Tibetan ice cores sounds reasonable, but it is not a definitive conclusion, since the difference in annual precipitation, the base topography, the dynamics of ice cap and the position of drilling core, all these factors may affect the base age of ice core extracted. Using only the ages is insufficient to argue the accuracy of the original chronology of Guliya ice core. The changes in chronology may induce significant change in the proxy time series, such as $\delta 180$ records. Actually, the authors have used the comparison of the $\delta 180$ record from Chongce ice core and other ice cores to argue the bottom ages of Guliya and Dunde ice cores. However, the comparison seems not so successful as show in the paper by Hou et al., (2019). If the proxy time series with these corrected bottom ages could also correlate with these two new ice cores, the arguments would be robust. So I suggest authors tempering the arguments, because there is no such direct dating results from those previously reported ice cores or proxy records comparisons.

As mentioned in the manuscript and also in two published papers (Hou et al., 2018; 2019), the bottom age of Dunde ice core has been changed close to $\sim 6.2 \mathrm{ka} \mathrm{BP}$ and the original chronology of this ice core has been corrected in the paper by Thompson et al. (2005). I suggest the author use this as an evidence to argue the Holocene origin of Tibetan Plateau, since the estimated bottom age and the original chronology have been corrected already. The argument in lines from 190 to 195 are meaningless and should be deleted.

For the discussion section, I suggest the authors change the subtitles a little bit, such as "the implication to the bottom age of XX ice cores".

Printer-friendly version

Discussion paper

Interactive comment on The Cryosphere Discuss., https://doi.org/10.5194/tc-2020-225, 2020. 